\title{
STRUCTURE OF RICE DEMAND AND CONSUMER LEXICOGRAPHIC PREFERENCES IN INDONESIA
}

\author{
Bidarti Agustina*, Husin Laila, Yulius \\ University of Sriwijaya, Indonesia \\ *E-mail: agustinabidarti@unsri.ac.id
}

\begin{abstract}
This research aims to identify the constraints in the distribution of rice before the enactment and after the implementation of HET in the demand structure of the three types of rice, head rice, medium rice and premium rice associated with changes in consumer lexicographic preferences. The study was conducted in urban and rural areas in Indonesia with cases in South Sumatra Province. 120 samples of rice consumers were selected in 60 rural and 60 urban consumers. The method of research is in depth study by observing and interviewing to exploring the variety of reasons for choosing lexicographic preferences in consuming all three types of rice, both in urban and rural areas. Susenas data is used to assess the structure of rice demand. Data analyzed by using quantitative and qualitative descriptive methods. The research results indicated that: (1) there was an increase in demand for medium and premium rice in rural and urban areas in the period 2013-2017, but decreased in the 2018-2019 period. This condition is due to the imposition of the Ceiling Price (HET) and inflation in 2018; (2) along with the factors affecting rice demand between rice times in rural and urban areas there are differences; (3) there are differences in the factors affecting the demand for rice between rural and urban rice. The structure of urban consumer demand remains influenced by quality factors, while rural is not; (4) based on a lexicographic analysis of rice demand in rural consumers more on the preference of physical attributes of rice and urban consumers to quality attributes, so that urban consumers of rice quality attributes continue to influence hedonic prices; (5) Based on the lexicograpphic function of household level demand for rice by the chow test, medium rice consumption in urban areas does not change the structure of consumption, but changes in rural areas. However, medium rice has been mixed with head rice, so it can be strongly suspected that urban consumers are the same as rural, that is, they do not yet have a proper understanding of good quality attributes for rice consumption. Unlike the urban consumers who still survive the consumption of premium rice that already has sufficient awareness and knowledge about the ins and outs of rice.
\end{abstract}

\section{KEY WORDS}

Demand structure, lexicographic preferences, ceiling price, rice types.

Rice is the main food in Indonesia. Rice is a problem because until now it is an irreplaceable consumption (Bidarti, 2018). South Sumatra Province is one of the rice food barns in Indonesia. Rice is a strategic commodity of main consumption. South Sumatra Province is one of the rice food barns in Indonesia. Rice is a strategic commodity. Rice as a primary consumption is a strategic commodity and a serious problem in distribution.

The purchasing power of the people towards rice is increasing. The demands of the people in consuming rice are increasingly varied. In Indonesian and South Sumatra province, rice is categorized in several qualities, namely premium, medium, head rice and subsidized rice (Bidarti \& Hartono, 2016; Bidarti, 2018). The rice is traded on traditional and modern markets. At the same time, there was a change in rice consumer preferences in South Sumatra. This preference is marked by an increase in public income, an increase in urban society, and the growth of modern retail. Changes in the factor of taste in the quality and quality of rice cause changes in the structure of rice demand from year to year.

In theory, the characteristics of consumer preferences in buying rice are difficult to explain with standard theory, because demand is not only influenced by one or two things 
alone, but various other factors in influencing the decision makers' preferences. Therefore, using lexicographic preferences can be sorted like a dictionary of various factors set of characteristics of decision making preferences (Sadilek, 2019; Panuntun Utami, 2011; Makarewicz, 2013).

Consumer preferences are defined as the subjective tastes of an individual as measured by utility, from various goods (Slottje, 2014; Lagerkvist, 2013) Lexicographic preference is a demand that is not only influenced by price and income factors but there are other factors that influence consumers in making decisions called lexicographic factors. The lexicographic consumer choice is the consumer's choice of a commodity based on a set of characteristics (Petri \& Voorneveld, 2015; Goswami, 2018). The main feature of lexicographic preferences is that a strong hierarchical record is defined in a particular set of desires. Desires that are satisfying tastes according to the components in the order specified.

The consumption patterns of rice commodities vary widely and tend to depend on several factors. For example, economic factors, social factors that include eating habits, education levels and tastes. There is an allegation that the rapid development of information technology has an effect on the shifting tastes of rice consumers in Indonesian and South Sumatra Province. If the consumption patterns of certain types of rice can be observed from time to time, it is likely that demand trends will be seen. To date, data on consumption patterns and trends in rice demand have not been reviewed. Is there a change in the structure of rice demand in line with various lexicographic preferences in the community? Then, what economic, social and cultural factors affect the demand for rice at the household level. Therefore, it is important to examine whether lexicographic preference factors affect rice demand in South Sumatra Province and in the segment of income level where lexicographic preference factors apply in South Sumatra Province.

\section{METHODS OF RESEARCH}

The data is supported by SUSENAS data of Indonesian rice in 2013, 2016 and 2019. The survey was conducted on 60 rice consumers in urban areas and 60 rice consumers in rural South Sumatra. South Sumatra Province was chosen because as the largest rice producer in Indonesian, and then selecting each of the 1 cities and 1 regency with the highest rice consumption in South Sumatra, namely Palembang City and Ogan Komering Ulu Timur (OKUT) District. Both of them were chosen to study the rice lexicography preferences of in urban areas and rural communities. Research data are processed and reported using tabulations, analyzed and described quantitatively and qualitatively.

\section{RESULTS AND DISCUSSION}

Rice Price Development and Consumer Revenues in South Sumatra. When viewed from the development of rice prices in rural South Sumatra before the implementation of Ceiling Price (HET), the price of rice of all types tends to increase. On the contrary, after the implementation of Ceiling Price (HET) since mid-2018, all rice prices showed a decline, except for the price of head rice. The decline in prices of premium rice from 2018 to 2019 was greater than the increase from 2016 to 2017. Whereas for medium rice, the magnitude of price increases from 2016 to 2017 is almost the same as price decreases from 2018 to 2019 (table 1).

Table 1 - Development of rice prices in rural South Sumatra

\begin{tabular}{ccccccccc}
\hline \multirow{2}{*}{ No } & \multirow{2}{*}{ Rice type } & \multicolumn{7}{c}{ Years } \\
\cline { 3 - 9 } & & 2013 & 2014 & 2015 & 2016 & 2017 & 2018 & 2019 \\
\hline 1 & Premium rice & 11.250 & 12.000 & 13.000 & 13.500 & 15.000 & 17.500 & 12.800 \\
2 & Medium rice & 10.914 & 11.192 & 12.200 & 12.500 & 13.500 & 14.000 & 9.800 \\
3 & Head rice & 6.280 & 6.100 & 6.200 & 7.000 & 8.000 & 8.350 & 9.800 \\
\hline
\end{tabular}

Source: SUSENAS data. 
Based on table 1 in the period of 2013 to 2016 there was a sharp increase in the price of medium rice by almost 10 percent, while from 2017 to 2018, the price increase is only around 5.8 percent. But the price of rice has declined dramatically, since the introduction of Ceiling Price (HET) mid-2018 to 2019, at around 15.5 percent. This indicates that the implementation of Ceiling Price (HET) in mid-2018 has the price shocks of medium rice in rural South Sumatra. This decline in rice prices did not affect the increasing purchasing power of consumers in the countryside. Because at the same time the implementation of the Ceiling Price (HET), the economic conditions of rural communities in South Sumatra were hit by inflation. Inflation causes a decrease in prices, rice, rubber and palm oil so that it has an impact on the decline in the level of rural household consumption of medium rice.

Whereas the increase in the price of head rice in rural areas after the Ceiling Price (HET) can be attributed to the general phenomenon of loss of premium rice and medium rice in the minimarket and shopping markets that occur in rural areas. As a result there is an increase in the supply of head rice in rural areas. Increased demand for head rice revived village mills that produce head rice. Head rice production makes direct sales of grain at cash prices obtained by rice farmers. So that rural farmers receive cash that can be used for family savings.

The development of rice prices in urban areas is different from that in rural areas. The price of premium rice and medium rice continues to increase before the entry into force of Ceiling Price (HET), starting from 2013 until mid-2018. But after the implementation of the Ceiling Price (HET) there was a decline in rice prices until 2019. The decline in the price of premium and medium rice in the city market has another impact, namely rice producers reducing the quality of premium rice and medium rice by making mixed with head rice.

Table 2 - Development of rice prices in urban South Sumatra

\begin{tabular}{ccccccccc}
\hline \multirow{2}{*}{ No } & \multirow{2}{*}{ Rice type } & \multicolumn{9}{c}{ Years } \\
\cline { 3 - 9 } & & 2013 & 2014 & 2015 & 2016 & 2017 & 2018 & 2019 \\
\hline 1 & Premium rice & 12.500 & 13.300 & 13.500 & 15.500 & 17.000 & 20.500 & 12.800 \\
2 & Medium rice & 11.500 & 12.000 & 12.200 & 13.500 & 14.500 & 17.500 & 9.800 \\
3 & Head rice & 7.000 & 6.500 & 6.500 & 7.000 & 7.500 & 8.000 & 9.800 \\
\hline
\end{tabular}

Source: SUSENAS data.

This condition is similar to what happened in rural areas, a decrease in the price of rice after the implementation of Ceiling Price (HET) on premium rice and medium rice, together with the declining quality of both types of rice. In the end, although premium and medium rice declined, but because it was followed by a decrease in quality, the purchasing power of urban communities for premium and medium rice was reduced. When there is an increase in the price of premium rice and medium rice accompanied by quality rice in accordance with the price, it is still followed by high demand and purchasing power of the city community. The reason for these two types of rice, because compared to the type of head rice, medium rice and premium rice still reflects that branded rice is a luxury commodity (table 2).

Factors Affecting Rice Demand between Periods. Based on the results of the analysis of the structure of rice demand in rural South Sumatra, there are several variables that affect rice demand between observational periods in the SUSENAS data. In period three (2019), the variable level of household income (InExps) did not significantly affect the demand for rice in rural South Sumatra with a $90 \%$ confidence level and a regression coefficient of 3.8642. This happens because it is still close to the implementation of the Ceiling Price (HET) in Indonesia in mid-2018, where the purchasing power of the rice consumer community is experiencing problems, caused by a decrease in the price of rice and a decrease in the quality of production of premium rice and medium rice by rice agro-industry companies in South Sumatra. In period one (2013) and period two (2016) the level of elasticity was higher than in period three (2019). This indicates that in period three, medium rice began to become a substitute for head rice. Medium rice in rural South Sumatra has become a staple item with a more luxurious economy compared to 2019. 
In the urban community of South Sumatra, in period one (2013) and period two (2016) the variable number of family members (InJang) significantly affected the demand for medium rice at $99 \%$ and $98 \%$ confidence levels with a regression coefficient of -1.8412 and 1.2246. As for the education level variable (InPdd) in period one and period two, it had a significant positive effect on demand for medium and premium rice at a 95\% confidence level. This can be interpreted that the higher the education levels of respondents, the higher the level of family consumption of medium and premium rice. Urban communities consume more medium and premium rice. They reduce consumption of head rice. For the people of the city, rice heads have a cheaper economic nature, because they are not branded and of low quality.

Lexicographic Analysis of Rice Demand in South Sumatra. It is suspected that along with the progress of the era on the one hand and the imposition of the highest retail price (HET) of rice in Indonesia, including in South Sumatra, people's purchasing power over rice has two trends. Firstly the increasing supply of head rice mixed with medium rice on the market. Secondly, the occurrence of inflation, both in urban and rural areas has reduced people's purchasing power.

Table 3 - Results of hedonic price (WTP) analysis of head rice, medium and premium rice in South Sumatra

\begin{tabular}{|c|c|c|c|c|c|c|}
\hline \multirow{2}{*}{ Variable } & \multicolumn{2}{|c|}{ Head Rice } & \multicolumn{2}{|c|}{ Medium Rice } & \multicolumn{2}{|c|}{ Premium Rice } \\
\hline & Reg.coef & t-ratio & Reg.coef & t-ratio & Reg.coef & t-ratio \\
\hline Rice Physical & $622.39^{* * *}$ & 6.052 & $-242.92^{\star \star *}$ & -5.139 & $-409.76^{\star \star \star}$ & -5.694 \\
\hline Rice Quality & $-532.06^{\star *}$ & -1.391 & $820.92^{* * *}$ & 4.490 & $238.06^{\star * *}$ & 3.624 \\
\hline Other attributes & $-590.66^{\star * *}$ & -2.070 & $409.05^{\star \star *}$ & 4.712 & $632.63^{\star \star \star}$ & 2.749 \\
\hline $\mathrm{R}^{2}$ & \multicolumn{2}{|c|}{0.1924} & \multicolumn{2}{|c|}{0.3608} & \multicolumn{2}{|c|}{0.2762} \\
\hline $\mathrm{F}$ & \multicolumn{2}{|c|}{$22,872^{\star \star *}$} & \multicolumn{2}{|c|}{$12.516^{\star \star \star}$} & \multicolumn{2}{|c|}{$7.762^{\star \star \star}$} \\
\hline
\end{tabular}

Source: Primary Data Analysis (2019).

Note: ${ }^{* *}$ ) significant $\left.\alpha=1 \% ;{ }^{* *}\right)$ significant $\alpha=5 \%$; *) significant $\alpha=10 \%$.

In general, both in urban and rural areas in South Sumatra, the physical attributes of head rice have a significant effect on its hedonic prices. The regression coefficient number is between the regression coefficients for the physical attributes of rice variables in rural areas and the physical attributes of rice in urban areas. Variable attributes of rice quality from head rice significantly affect hedonic prices both in rural and urban areas. In general, both in urban and rural areas, the quality attribute of rice from medium rice influences its hedonic prices. Meanwhile, for premium rice, both in urban and rural areas, in general the quality of premium rice influences its hedonic prices.

Lexicographic Functions for Household Level Rice Demand in Urban and Rural Areas. The rice demand function is based on lexicographic preferences for head rice, medium rice and premium rice in besides to entering the demand function variable based on common demand theory, i.e. demand is a function of price and income also included variables. These variables are characteristic variables, demographic variables and social variables. Specifically for the household income variable due to the complexity of the problems for surveying income variables, what is included in the analysis is income data that is approached from household expenditure.

Based on the results of the chow test analysis above, consumption of head rice in urban and rural areas from time to time from 2013, 2016 and 2019 changes in the structure of consumption. From the results of hedonic price analysis, it appears that the physical attributes of rice and other attributes significantly affect the price of hedonic rice in urban and rural areas in South Sumatra.

The inclusion of hedonic price estimation values as a variable instrument in the lexicographic function of rice demand is intended to reflect consumer preferences or choices of the elements of rice characteristics that exist in the hedonic price function in the form of physical attributes of rice and other attributes. When examined further from the lexicographic analysis of rice demand, both hedonic prices and quality of rice did not significantly affect demand for head rice in urban and rural communities in South Sumatra. 
Table 4 - Analysis of Rice Consumption in South Sumatra based on Lexicographic preference

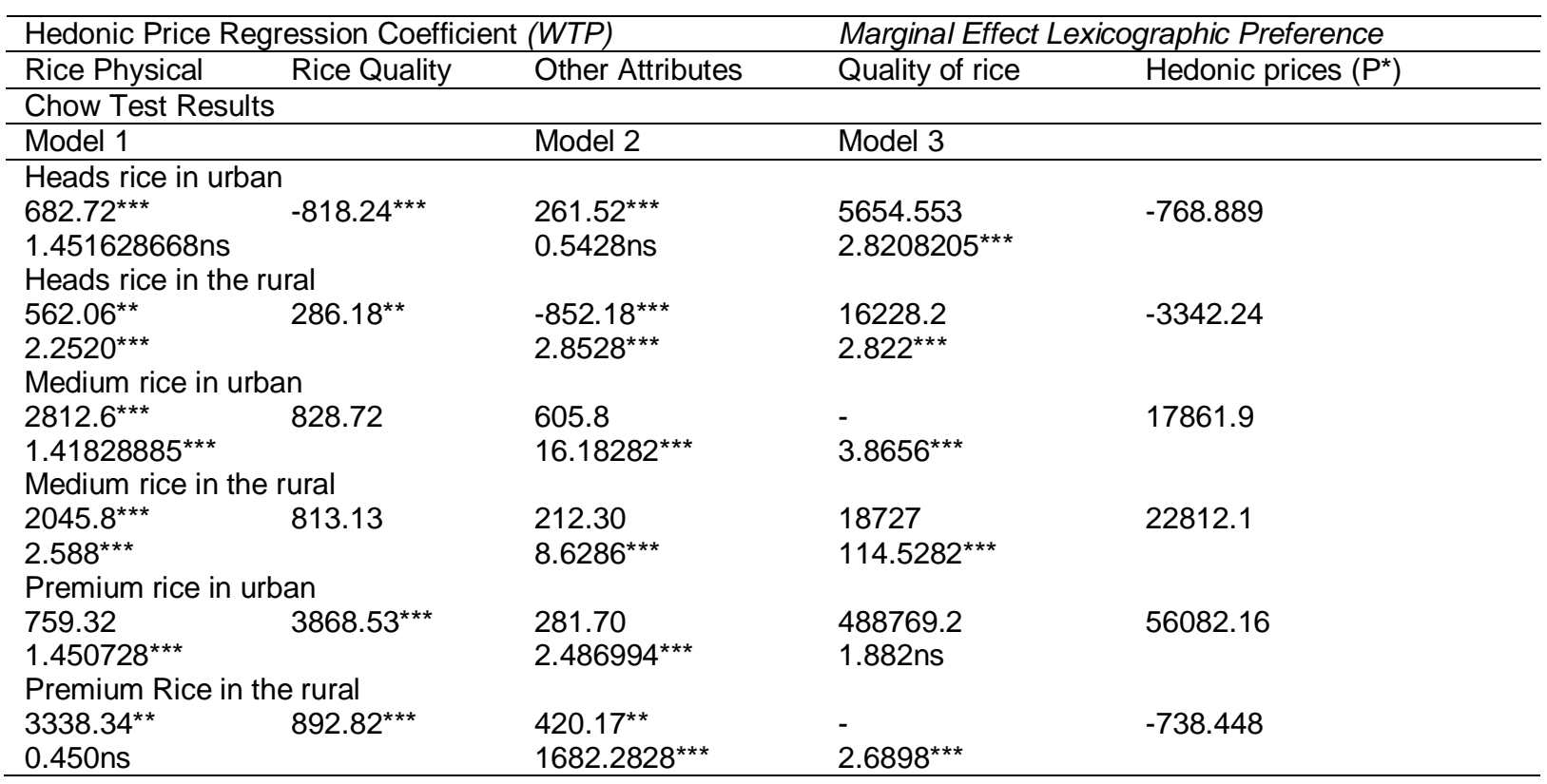

Source: Primary Data Analysis (2019).

Note: ns) no significant; ${ }^{* *}$ ) Significant $95 \%$ confidence level; ${ }^{* * *}$ Significant $99 \%$ confidence level.

These conditions can be interpreted that rice consumers do not consider the quality and characteristics of rice that are quality attributes are a priority in choosing the head rice they will consume. However, there is a tendency that in urban and rural areas the physical attributes of rice and other attributes are taken into account by consumers in choosing head rice. To find out, to what extent consumers take this attitude, researchers consider further research is needed. Chow test analysis results (table 4), medium rice consumption in urban areas from time to time from 2013, 2016 and 2019 did not change the structure of consumption. But in rural areas there is a change in the structure of consumption.

Based on the results of the analysis of medium hedonic rice prices in table 4, it was found that in urban and rural areas, quality attributes affect the medium hedonic rice prices, but on the other hand other attributes do not affect. This is strongly suspected to be a resemblance to what happened to head rice. Consumers do not have a proper understanding of good quality attributes for consumption. Meanwhile, the consumption of premium rice in urban and rural areas from time to time during the 2013, 2016 and 2019 periods there was a change in the consumption structure. Based on the results of the analysis of premium rice hedonic prices (table 4) it was found that in urban and rural areas, quality attributes affect the price of premium rice hedonic. But for physical attributes and other attributes that have no significant effect on hedonic prices. This condition is related to the absence of proper consumer knowledge regarding the ins and outs of premium rice.

When examined further from the results of a lexicographic analysis of rice demand in urban and rural communities in South Sumatra, no significant effect of the hedonic price variable or rice quality variable was found on its demand. Therefore, it can be explained that the quality attributes for the characteristics of premium rice are only at the level of consideration, not as the primary choice of consumers in determining premium rice consumption.

\section{CONCLUSION}

The change in the structure of consumption of premium and medium rice to head rice in rural communities in South Sumatra can be accessed from the price elasticity itself. The 2016 period is more elastic than the 2013 period, while the 2019 period is more elastic than the 2013 period. In urban communities, when viewed from the income elasticity in the 2019 
period more elastic than the 2013 period, while the 2016 period is no different from the 2013 period. Changes in the structure of consumption are likely to be caused by the impact of the implementation of HET and inflation in the prices of major commodities in rural areas, such as rubber and palm oil, which began to occur in 2018.

Lexicographic factors that generally have a significant effect on demand are different for each type of rice. There is a gap between the knowledge consumers have about the characteristics of rice which is associated with rice quality, income level, education regarding health and food safety, with the attitude taken to consume or not consume this type of rice. This condition is due to the knowledge possessed by consumers about the intricacies of the characteristics of rice actually has not been supported by a correct understanding. Consumer knowledge has not had a strong role in being to determine choices, consume or not consume.

\section{AKCNOWLEDGEMENTS}

This paper is part of the Grant Competitive University of Sriwijaya Research in 2019, which has been funded this research complies with the letter of Agreement Assignment of Competitive Grants Research University of Sriwijaya in 2019.

\section{REFERENCES}

1. Bidarti, A (2018). Manajemen Rantai Pasok (Supply Chain Management) Beras Kasus CV Lintas Indo Comodity Mandiri di Sumatera Selatan. Disertation of Gadjah Mada University, Yogyakarta.

2. Bidarti, A., \& Hartono, S (2016). "Suppliers Structure And Performance Evaluation Supplier Network Stagein The Supply Chain Management Of Rice In South Sumatra”, in Advances In Global Business Research, 13 (1): 2536-2549.

3. Sadilek, T (2019). "Perception of Food Quality by Consumers: Literature Review", European Research Studies Journal, 22(1): 52-62.

4. Panuntun Utami, D (2011). "Analisis Pilihan Konsumen Dalam Mengkonsumsi Beras Organik Di Kabupaten Sragen", Jurnal Mediagro, 7(1): 41-58.

5. Makarewicz, A (2013). "Consumer behavior as a fundamental requirement for effective operations of companies", Journal of International Studies, 6(1): 103-109.

6. Slottje, D (2014). Quantifying Consumer Preferences. London UK: Emerald Group Publishing Ltd.

7. Lagerkvist, C.J (2013). "Consumer preferences for food labelling attributes: Comparing direct ranking and best-worst scaling for measurement of attribute importance, preference intensity and attribute dominance," Journal Food Quality and Preference, 29(2): 77-78.

8. Petri, H., \& Voorneveld, M (2016). "Characterizing Lexicographic Preferences", Journal of Mathematical Economics, 63: 1-12.

9. Goswami, M.P., Mitra, M., \& Sen, D (2017): A characterization of lexicographic preferences. MPRA_paper_90552.pdf. Accessed March 12, 2019. 